\title{
O SENTIDO POLIITICO DO REALISMO DE MACHADO DE ASSIS NA CRÍTICA LITERÁRIA DOS ANOS 1970: OS ENSAIOS DE CARLOS NELSON COUTINHO
}

Gabriela Manduca Ferreira

RESUMO: O presente estudo, a partir da observação de interpretações do realismo machadiano construídas pela crítica literária durante os anos 1970, analisa os ensaios sobre literatura de Carlos Nelson Coutinho, a fim de investigar o sentido político dos estudos sobre o realismo machadiano no período.

PALAVRAS-CHAVE: Crítica machadiana; Realismo; Machado de Assis.

ABSTRACT: This study pinpoints the readings of the Machadian realism constructed by literary critique of the 1970s. The article precisely analyses Carlos Nelson Coutinho' essays on literature and has as its central objective to investigate the political meaning of the readings of Machadian realism.

KEYWORDS: Machadian critique; Realism; Machado de Assis. 
Ao longo do século xx a interpretação de Machado de Assis sofreu uma inflexão, passando a observar os vínculos críticos da obra machadiana com a realidade local e a compreender sua universalidade como concretamente alcançada pela mediação com a realidade brasileira. Diante dessa mudança na interpretação da obra de Machado, localizada principalmente entre os anos 1930 e 1940, o realismo na obra machadiana tornou-se uma questão central para a crítica do período, marcada pelas contribuições de Augusto Meyer, Astrojildo Pereira, Eugênio Gomes e Lúcia Miguel Pereira

A discussão, que havia arrefecido nos anos 1950 e 1960 (com maior investimento no estudo da dimensão formal da obra literária), retornou nos anos 1970 propiciada por uma conjunção de fatores que faziam do realismo de Machado de Assis motivo de interesse crítico: um novo regime autoritário no país; uma nova consagração oficial do escritor; a mobilização de novos instrumentais teóricos e metodológicos para o estudo da literatura; e a consolidação da crítica universitária.

Desse modo, o estudo do realismo na obra de Machado se impôs a diferentes críticos da geração de 1970, conformando, novamente (e em outras bases) - com continuidades e rupturas em relação às afirmações críticas dos anos 1930 -, um interesse crítico comum. Nesse período foram críticos como Alfredo Bosi, Carlos Nelson Coutinho, Jean Michel Massa, Luiz Costa Lima, Raymundo Faoro e Roberto Schwarz que tomaram Machado de Assis como objeto de estudo.

Assim, a caracterização do realismo na obra machadiana constituiu o traço marcante e a preocupação comum às duas gerações críticas. Novamente, tratou-se de identificar a existência de vínculos de Machado de Assis, nesse caso de sua obra, com a realidade social. Os instrumentais utilizados e os resultados críticos foram os mais diversos, mas, nos dois períodos, tornou-se uma necessidade responder sobre o modo como o autor de Dom Casmurro representou, mimetizou, transfigurou, imitou ou interpretou a realidade.

Neste estudo, sustentamos, portanto, que as interpretações do realismo na obra machadiana construídas em torno dos anos 1970 correspondem, reagem e revelam as obsessões de seu tempo (para parafrasear a expressão de Antonio Candido no "Esquema de Machado de Assis"), ${ }^{1}$ entendendo que o interesse pela identificação dos vínculos do escritor com a realidade decorre, por um lado, do interesse pela realidade brasileira e,

1 CANDido, Antonio. "Esquema de Machado de Assis". In: Vários escritos. São Paulo: Duas Cidades, 1970. 
por outro lado, do interesse pelo significado de Machado de Assis para a vida social brasileira e pelo próprio sentido político que tal significado inevitavelmente guarda.

Assim, o que foi apenas esboçado na geração de 1930, em relações dúbias com o Estado amenizadas ainda pela rara explicitação de referenciais teóricos e por interpretações muitas vezes impressionistas, transformou-se de fato em problema crítico para a geração dos anos 1970, munida de instrumentais teóricos mais precisos, porém já exposta ao terror de Estado, polarizada, fragmentada, perseguida e tendo de tomar de assalto ao aparato oficial o "grande escritor nacional".

Nesse momento, a discussão em torno do realismo na obra machadiana projetou-se na definição de mimese adotada pelos críticos e também na identificação de uma dialética do texto machadiano capaz de articular diferentes dimensões, daí as relações estabelecidas entre o realismo de Machado de Assis e o caráter mimético e dialético de sua obra.

Certamente, como toda a realidade, a situação das correntes crítico-literárias em cena nos anos 1970 era, no mínimo, contraditória, de uma "riqueza contraditória", na definição de Alfredo Bosi, ${ }^{2}$ e precisa ser nuançada. Ao escrever sobre seu percurso intelectual, Bosi descreve as correntes críticas em disputa com que se deparou nas décadas de 1960 e 1970:

Quem viveu aqueles anos turbulentos da história brasileira convirá comigo que não é fácil ordenar didaticamente a riqueza contraditória de correntes e contracorrentes culturais que caracterizou tanto o período anterior ao golpe militar de 1964 quanto os chamados anos de chumbo, que avançaram pelo decênio seguinte. As tendências superpunham-se ou baralhavam-se. O existencialismo cedia ao marxismo (era o caminho de Sartre, então o guru dos intelectuais inconformistas), ou então refluía para suas origens fenomenológicas, pela ação de Ricoeur e de Gadamer, mestres da hermenêutica, aqui representada pelas propostas da revista Tempo Brasileiro dirigida por Eduardo Portella. No campo da análise literária, a Estilística, que dependia, em parte, da estética crociana da expressão, era descartada pelo estruturalismo ou, mais genericamente, pelo formalismo. Este, tangido pela censura estalinista, se deslocara do mundo eslavo para a França, e tinha como figura inspiradora o grande linguista Roman Jakobson, que teorizara as funções da linguagem. ${ }^{3}$

2 воsI, Alfredo. "Caminhos entre a literatura e a história”. Estudos Avançados, n. 19, vol. 55, pp. 315-34, 2005 , p. 318.

3 Idem, p. 318. 
Ao analisar a crítica machadiana da década de 1970, outro crítico do período, Luiz Costa Lima, ${ }^{4}$ relacionou as concepções de mimese presentes na obra lukacsiana com os conceitos de mimese desenvolvidos pela crítica literária brasileira a partir do golpe de 1964. Além disso, de acordo com Lima, o golpe de 1964 teve entre seus rebatimentos um "incremento do interesse na obra de nosso grande escritor do século xix, Machado", gerando estudos machadianos que participavam do "esforço de dar um novo rumo ao pensamento nacional, através de uma área que, não sendo diretamente política, seria mais dificilmente reprimida". ${ }^{6}$

A partir da afirmação de Costa Lima, podemos observar que a crítica machadiana se constituía na década de 1970 como um espaço de oposição ao pensamento conservador e de refúgio para a crítica social. Ao mesmo motivo Lima atribuiu a ênfase na questão da mimese na crítica da década de 1970, vista como "resposta a uma ditadura voltada para extirpar tudo que se contrapusesse à ordenação tradicional da sociedade".

De fato, os anos 1970 concentram uma problematização da crítica literária, de seu comprometimento ideológico e da possibilidade de que ela se constituísse em um espaço de crítica social e de refúgio para a militância política. Sob esse aspecto, tal discussão se revela de modo decisivo nos escritos de Carlos Nelson Coutinho.

Embora Carlos Nelson Coutinho não possa ser considerado um crítico machadiano (pois seus ensaios tocam Machado de Assis quase sempre tangencialmente) e tenha uma produção sobre literatura restrita à década de 1970, a escolha da crítica literária dele como objeto deste estudo justifica-se por estes fatores: uma das preocupações centrais dos ensaios do autor sobre arte e cultura é o realismo, questão central para sua geração; ele opera na crítica literária a partir do conceito lukacsiano de realismo, conceito discutido/mobilizado por outros críticos do período; e sua produção de crítica cultural circunscrita aos anos de regime militar indica uma profunda relação entre seus ensaios e a realidade política do país no período.

\footnotetext{
4 LIMA, Luiz Costa. Mímesis: elaboração contra imitatio. Entrevista concedida em 9 abr. 2016 para pesquisa de doutorado. In: FERreIRA, Gabriela Manduca. Interpretações do realismo na obra de Machado de Assis: realidade, política e crítica nos regimes autoritários brasileiros. Tese (Doutorado em Literatura Brasileira), São Paulo, Faculdade de Filosofia, Letras e Ciências Humanas da Universidade de São Paulo, 2016, p. 284.

5 LIMA, Luiz Costa. Mímesis: elaboração contra imitatio, cit., p. 284.

6 Ibidem.

7 Ibidem.
} 
Reconhecido filósofo e cientista político, Carlos Nelson Coutinho (1943-2012) graduou-se em Filosofia pela Universidade Federal da Bahia em 1965; viveu durante o regime militar exilado na Itália até 1979; em 1986, tornou-se professor titular de Teoria Política na Universidade Federal do Rio de Janeiro e, em 2012, professor emérito, falecendo poucos meses depois, em 20 de setembro de 2012. Foi também militante do Partido Comunista Brasileiro (РСв) desde a juventude, tendo, a partir dos anos 1980, militado no Partido dos Trabalhadores (PT), onde permaneceu até a fundação do Partido Socialismo e Liberdade (PSOL).

O reconhecimento de Carlos Nelson Coutinho como um dos principais intelectuais marxistas do Brasil está mais fortemente vinculado à sua contribuição para os estudos em teoria política e pensamento político, tendo sido descrito com frequência como "um dos maiores especialistas no pensamento de Gramsci", reforçar o entendimento de Coutinho como um "crítico momentâneo das letras".

No presente estudo, partiremos da análise do ensaio "O significado de Lima Barreto na Literatura Brasileira,", publicado em 1974 no livro Realismo e antirrealismo na literatura brasileira, a fim de apreendermos alguns posicionamentos de Carlos Nelson Coutinho sobre a obra machadiana. Isto porque, partindo das relações entre literatura e sociedade, Carlos Nelson Coutinho nesse ensaio mobiliza a interpretação de Machado de Assis para a comparação com Lima Barreto.

Ao descrever os equívocos da crítica relacionados à obra de Lima Barreto, como o "entusiasmo apaixonado", o "desprezo aristocrático" e o "biografismo", ${ }_{11}^{11}$ defendendo que passou despercebida a essa crítica a "exata significação de Lima Barreto", Coutinho busca identificar o "significado de Lima Barreto na evolução da literatura brasileira", fazendo, contudo, a ressalva de que abordaria a questão "não apenas no específico

8 BIANCHI, Álvaro. “Entrevista com Carlos Nelson Coutinho”. Cult, n. 141, São Paulo, mar. 201o. Disponível em: <http://revistacult.uol.com.br/home/2010/o3/entrevista-com-carlos-nelson-coutinho/>. Acesso em: 16 jun. 2016, s. p.

9 Frederico, Celso. "Presença de Lukács na política cultural do РСв e na universidade". In: MORAes, João Quartim de (org.). História do marxismo no Brasil, vol. 2. Os influxos teóricos. Campinas: Editora da Unicamp, 2007, p. 202.

10 coutinho, Carlos Nelson. "O significado de Lima Barreto na literatura brasileira”. In: coutinho, Carlos Nelson et al. Realismo e antirrealismo na literatura brasileira. Rio de Janeiro: Paz e Terra, 1974. 11 Idem, p. 2. 
campo dos problemas estéticos, mas igualmente no que se refere ao quadro histórico-social em que ela se processa". ${ }^{2}$

Para isso Coutinho ${ }^{13}$ se vale do conceito leniniano de "via prussiana". Segundo a formulação de Lenin, a passagem ao capitalismo na Rússia se dera de modo diferente das "vias clássicas", isto é, por uma "via prussiana", na qual a entrada tardia no capitalismo conserva elementos do pré-capitalismo. Coutinho entende tal conceito de "via prussiana" como de alcance e aplicabilidade universal, manifestando-se em países como Rússia, Brasil e Japão, e defende que no Brasil a "via prussiana” para o capitalismo trouxe profundas consequências para a intelectualidade, sendo uma delas o desenvolvimento de uma tendência de "intimismo à sombra do poder", caracterizada como uma tendência dos intelectuais brasileiros a "evadir-se da realidade", acentuando o "isolamento com relação à concreta realidade nacional-popular". ${ }^{14}$

Para o caso brasileiro, Coutinho ${ }^{15}$ interpreta que as conciliações com o atraso produziram um "intimismo à sombra do poder" de tipo específico, aqui marcado pelo fato de que "os intelectuais dependiam para o seu sustento, quase sempre, de uma integração no aparelho burocrático do Estado" ${ }^{16}$

$\mathrm{Na}$ literatura brasileira, esse "intimismo à sombra do poder" se revela, segundo Coutinho, tanto no romantismo como no naturalismo: no romantismo, "cumprindo uma função basicamente escapista", servindo "claramente a finalidades de ocultamento das contradições essenciais da realidade" ou "à expressão quase exclusiva de problemas privados e superficiais"; ${ }^{17}$ e no naturalismo, que, sem representar uma "ruptura essencial com a tradição romântica", transformou "o protesto originário dos naturalistas em conformismo real, numa resignada aceitação das misérias humanas que descreviam em seus romances". ${ }^{18}$

Coutinho reconhece que as condições brasileiras, descritas como "condições de um país semifeudal imerso na 'via prussiana' de desenvolvimento", dificultam a supera-

\footnotetext{
12 Idem, p. 3.

13 Ibidem.

14 Idem, p. 4.

15 Ibidem.

16 Ibidem.

17 Idem, p. 6.

18 Idem, p. 7 .
} 
ção do "intimismo à sombra do poder", tornando a "criação de autênticas obras estéticas realistas $[\ldots]$ altamente problemática”. ${ }^{19}$

Por isso, alguns autores e obras são considerados por Coutinho ${ }^{20}$ como os responsáveis pelos raros momentos de "vitórias do realismo" (expressão de Engels), momentos em que tanto o "intimismo à sombra do poder" como a "pobreza humana objetiva da realidade social" são contornados. As "vitórias do realismo" destacadas por Coutinho são: a lírica brasileira, desde a lírica de inspiração romântica, com "um intenso pathos subjetivo de recusa e inconformismo", ${ }^{21}$ tendo Castro Alves como o principal exemplo de "superação lírica dos limites impostos pelo 'intimismo' dominante"; ${ }^{22}$ Memórias de um Sargento de Milícias, de Manuel Antônio de Almeida, interpretado como um romance "que figura concretamente, de modo imediatamente estético, as alternativas democráticas do povo brasileiro"; ${ }^{23}$ e, "bem mais complexo e completamente diverso", o Machado de Assis da maturidade, que "logrou alcançar uma plena e profunda vitória do realismo". ${ }^{24}$

O livro em que foi publicado o ensaio, Realismo e antirrealismo na literatura brasileira, é composto também por artigos de Luiz Sérgio Nascimento Henriques, Leandro Konder, Gilvan Procópio Ribeiro e José Paulo Netto, todos ensaios que partem do conceito lukacsiano de realismo para analisar a literatura brasileira.

Em raro comentário sobre o livro, publicado na revista Discurso (vol. 5, n. 5), o filósofo Luiz Fernando Franklin de Matos considerou a obra uma contribuição relevante para os "tempos obscuros em que nossa produção literária vem sendo assimilada às camisas de força da ideologia estruturalista", compreendendo que a principal qualidade do livro é realizar uma "investigação lukacsiana da literatura brasileira", pois isso permitiu propor "horizontes menos restritos, subtraindo a investigação dos conhecidos delírios de ordem tecnicista". Para o articulista, no entanto, o ensaio de Carlos Nelson Coutinho sobre Lima Barreto está "amarrado em demasia aos esquemas lukacsianos de pesquisa".

\footnotetext{
19 Coutinho, Carlos Nelson. “O significado de Lima Barreto na literatura brasileira”, cit., p. 9.

20 Idem, p. 8.

21 Ibidem.

22 Ibidem.

23 Idem, p. 10.

24 Ibidem.
} 
No prefácio de Realismo e antirrealismo na literatura brasileira está explícita a intenção de realizar análises da literatura brasileira a partir da teoria de Lukács:

Os ensaios reunidos no presente volume têm em comum, ao lado das diferenças naturais de tom e estilo, o fato de serem tentativas de interpretação e reavaliação de importantes questões da literatura brasileira à luz das ideias estéticas de Lukács. ${ }^{25}$

Mas outro objetivo também fica exposto no prefácio: o de, contrapondo-se às análises literárias formalistas e estruturalistas, "reintroduzir no pensamento estético de nosso país a preocupação teórica com os problemas do realismo" ${ }^{26} \mathrm{O}$ livro insere-se, portanto, no esforço militante de contrapor-se ao abandono das preocupações sociais ocasionado pela repressão do regime militar. Esforço que, embora compreensível, não encobre a instrumentalização da crítica literária empreendida por esse grupo:

Há que se entender [...] o clima que propiciou o nascimento de Realismo e antirrealismo na literatura brasileira, bem como perdoar a irritação desses jovens indignados que escolheram a crítica literária para denunciar o abandono das preocupações sociais por boa parte de uma intelectualidade intimidada. Mas há que se observar também que a instrumentalização da crítica literária não ajuda em nada a política cultural daqueles que querem conquistar a hegemonia entre os artistas e os intelectuais. A tentativa destemperada de imitar os piores momentos de Lukács [...] serviu apenas para aumentar a suspeita de que os comunistas pretendiam patrulhar a criação artística. ${ }^{27}$

Esse dado torna-se relevante ao observarmos a recepção da obra de Lukács no Brasil e as circunstâncias sob as quais esse grupo de intelectuais produziu os ensaios de crítica literária em questão. Ao abordar a recepção das ideias de Lukács no Brasil, Celso Frederico afirma que ela "deu-se basicamente pela jovem intelectualidade comunista e não através da universidade". ${ }^{28} \mathrm{E}$ entre a jovem intelectualidade comunista estava Carlos Nelson Coutinho.

\footnotetext{
25 Coutinho, Carlos Nelson et al. Realismo e antirrealismo na literatura brasileira, cit., p. Ix.

26 Idem, p. x.

27 Frederico, Celso. "Presença de Lukács na política cultural do РСв e na universidade", cit., p. 206.

28 Idem, p. 187.
} 
Assim, Frederico localiza o principal período de ampliação da divulgação da obra de Lukács no Brasil no pós-1964, atribuindo isso, por um lado, ao movimento internacional de renovação do comunismo e, por outro, à situação da esquerda brasileira, derrotada pelo golpe de 1964. Nesse contexto, um grupo de jovens, entre vinte e 25 anos, "dedicou todos os seus esforços para tornar Lukács uma referência obrigatória nos debates intelectuais": ${ }^{29}$

A divulgação da obra de Lukács, assim, esteve inicialmente nas mãos de jovens intelectuais, quase todos gravitando ao redor dо РСв, que atuavam no Rio de Janeiro (Leandro Konder, Carlos Nelson Coutinho), em São Paulo (José Chasin, José Carlos Bruni) e, posteriormente, em Juiz de Fora (José Paulo Netto, Gilvan Procópio Ribeiro e Luiz Sérgio Henriques)..$^{30}$

Ainda sobre o contexto de atuação desses lukacsianos, é relevante indicar que o golpe de 1964, controlando a participação política institucional, transformou a cultura em um polo de resistência ao regime militar, o que levou o grupo, segundo Frederico sem

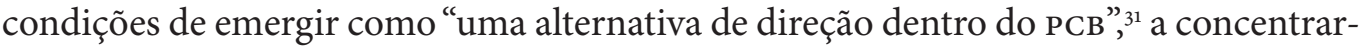
se no campo da política cultural.

Mas foram a intervenção crescente do regime militar na área cultural e a repressão e perseguição aos intelectuais no pós-68 que levaram esse grupo a incursões na crítica literária, ainda que sua intenção fosse discutir a política:

Impedidos de travar uma polêmica aberta contra a intromissão do regime na vida cultural e contra o conformismo e desvario em que mergulharam muitos artistas e intelectuais, os publicistas lukacsianos confinaram-se no terreno aparentemente insuspeito da crítica literária. Sem traquejo para tratar de textos literários, transformaram-se em críticos momentâneos das letras e passaram a falar de literatura quando, na verdade, pretendiam falar da política em geral e de política cultural em particular..$^{32}$

\footnotetext{
29 Idem, p. 194.

30 Ibidem.

31 Ibidem.

32 Idem, p. 202.
} 
Os conceitos lukacsianos foram, portanto, estrategicamente mobilizados, tanto para "se reestudar criticamente a literatura", ${ }^{33}$ como para, "em escala menor, se pensar temas da realidade brasileira". ${ }^{4}$

O movimento de, em contexto repressivo, refugiar-se na crítica literária para realizar crítica social não era exatamente raro e foi realizado, segundo José Paulo Netto, ${ }^{35}$ pelo próprio Lukács, tanto na Alemanha, como na União Soviética:

Escaldado pela derrota de Blum e continuando primordialmente preocupado em não ser alijado da luta antifascista por um afastamento qualquer do movimento comunista, Lukács combate aquela política nos estreitos limites da sua atividade como crítico literário - donde os seus debates acerca do impressionismo e contra o vanguardismo sectário da esquerda alemã. [...] [Na União Soviética] ele se recusou ao martírio e travou contra o stalinismo, nesses anos, o combate possível, que caracterizaria como o "combate espiritual de um partisan": defendeu, no plano estrito da cultura, ideias colidentes com a doutrina oficial, mas sempre protegendo-se com citações protocolares de Stalin e com uma intencional restrição de seus juízos à esfera cultural. ${ }^{36}$

A crítica literária consistiria, portanto, em um refúgio pertinente devido ao entendimento de Lukács de que há uma coincidência entre a forma da sociedade e a forma do gênero. Mais do que isso, porém, a literatura realista, para a teoria lukacsiana, poderia ser reveladora da realidade social. Como explica Oliveira: ${ }^{37}$

[...] da maneira como Lukács vê [as formas], falar do romance é falar da sociedade. [...] A forma do romance é a mesma do processo de mercantilização, que acontece fora do romance, tendo esta a particularidade de ser reveladora, ao contrário da maneira abstrata

\footnotetext{
33 Idem, p. 195.

34 Ibidem.

35 NETTO, José Paulo. "Introdução". In: LukÁcs, György. Socialismo e democracia: escritos políticos 19561971. Organização, introdução e tradução de Carlos Nelson Coutinho e José Paulo Netto. Rio de Janeiro: Editora UFRJ, 2008.

36 Idem, p. 16.

37 OLIVEIRA, Irenísia Torres de. “Sociedade e forma na crítica de Lukács, Candido e Schwarz”. XII Congresso Internacional da Abralic: Centro, Centros - Ética, Estética. UPPR - Curitiba, Brasil, 18 a 22 jul. 2011. Disponível em: <www.abralic.org.br/eventos/cong2011/AnaisOnline/.../TCo142-1.pdf>. Acesso em: 10 jun. 2016.
} 
com a qual o pensamento reificado apreende as coisas. A mercantilização não era algo que acontecia apenas fora de nós, mas era algo que permeava desde a produção do papel até o sentimento lírico. A virtude da forma, a forma do realismo, especificamente, era a do esclarecimento, que podia escapar à reificação e fornecer uma consciência crítica do processo..$^{38}$

No mesmo sentido Leandro Konder defende que "afirmar que a crítica estética pode prestar serviços à própria análise política não é heresia alguma, do ponto de vista marxista”, visto que Lukács, entre outros teóricos marxistas, serviu-se "de suas observações estéticas para tirar conclusões que implicavam consequências ideológicas e políticas".39

Devido, por um lado, ao contexto de recepção das ideias de Lukács no Brasil por um grupo de jovens intelectuais marxistas cerceados pela repressão do regime militar, e, por outro, devido à correspondência ${ }^{40}$ mantida entre Carlos Nelson Coutinho, Leandro Konder e o próprio Lukács de 1963 a 1970, a crítica literária realizada por Coutinho foi profundamente marcada pela obra lukacsiana.

Assim, nos estudos sobre literatura de Coutinho revelam-se alguns pressupostos metodológicos de formulação lukacsiana mobilizados para abordar a cultura e a literatura brasileira. Em "O realismo como categoria central da crítica marxista", ${ }^{41}$ Coutinho apresenta Lukács como um caminho para alcançar, no âmbito da crítica literária, "o reencontro das posições marxianas e leninianas", posicionando-se contra o revisionismo e o dogmatismo.

Esse caminho, para Coutinho, seria necessário para reaproximar o materialismo dialético-materialista do materialismo histórico-materialista, já que tal afastamento teria gerado o "sociologismo", uma "limitação do marxismo ao materialismo histórico" 42 que, embora pudesse ser mais vulgar ou menos vulgar (os dois exemplos são respectivamente Plekhânov e Goldmann), "caracteriza-se primariamente pelo fato de reduzir a obra de arte à sua gênese social". ${ }^{3}$

\footnotetext{
38 Idem, p. 4.

39 KONDER, Leandro. Os marxistas e a arte: breve estudo histórico-crítico de algumas tendências da estética marxista. Rio de Janeiro: Civilização Brasileira, 1967, p. 9.

40 A correspondência completa entre Carlos Nelson Coutinho, Leandro Konder e Lukács foi publicada em: PINASSI, M. O.; LeSSA, S. (orgs.). Lukács e a atualidade do marxismo. São Paulo: Boitempo, 2002.

41 Coutinho, Carlos Nelson. “O realismo como categoria central”. In: coutinho, Carlos Nelson. Literatura e humanismo: ensaios de crítica marxista. Rio de Janeiro: Paz e Terra, 1967, p. 96.

42 Idem, p. 97.

43 Idem, p. 98.
} 
Considerando que o marxismo possui uma estética própria contida já nos escritos de Marx e Engels, a qual entende "a arte como um reflexo da realidade objetiva e não apenas como 'expressão' de uma psicologia de classe", Coutinho defende a "crítica filosófica" proposta por Lukács em sua obra da maturidade como o meio para integrar "a análise da legalidade específica da arte" 44 e a "determinação do seu caráter histórico-social”.45 Porém, a marca de Lukács na crítica de Carlos Nelson Coutinho revela-se, segundo Frederico, tanto nos acertos quanto nos equívocos do autor:

Quando trabalha com autores realistas [...] C. N. Coutinho obtém excelentes resultados. Quando, ao contrário, esbarra em autores que escapam do método realista (Clarice Lispector, por exemplo), ele apenas repete o normativismo excludente dos piores momentos de Lukács. ${ }^{46}$

Talvez justamente a dificuldade em lidar com os romances que escapavam da conceituação lukacsiana de realismo tenha determinado a interpretação de Coutinho sobre Machado de Assis e, ao mesmo tempo, o fato de a obra machadiana não ter sido o objeto central de um estudo de Coutinho.

Desse modo, os ensaios de Carlos Nelson Coutinho que abordam a obra machadiana o fazem sempre em comparação com outros escritores e para indicar (em outros ensaios mais brevemente do que em "O significado de Lima Barreto") que Machado de Assis é uma das exceções de uma literatura "marcada objetivamente por um viés elitista" e "muitas vezes portadora de uma visão elitista".47

O entendimento do significado de Machado de Assis na Literatura Brasileira defendido por Coutinho relaciona-se, ainda, em alguns aspectos, com a interpretação de Nelson Werneck Sodré em História da literatura brasileira. ${ }^{48}$ Embora a perspectiva de "fidelidade" à realidade e a leitura biográfica da obra machadiana tenham sido amenizadas por Carlos Nelson Coutinho (1974), a visão sustentada por Sodré da obra

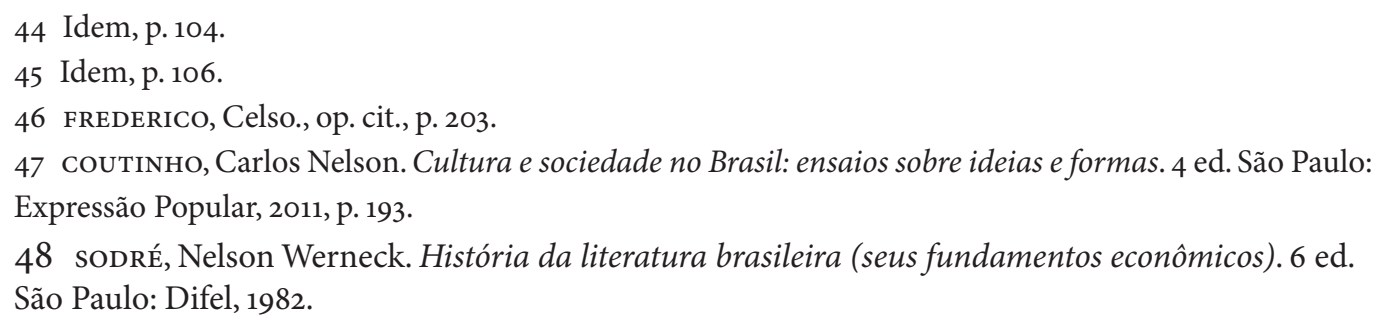


machadiana madura como de "posição realista inequívoca" e afastada da "forma de expressão" do naturalismo é desenvolvida por Coutinho (1974).

Em História da literatura brasileira Nelson Werneck Sodré apresenta Machado de Assis como "a grande figura literária do tempo e a maior que o nosso país conheceu". ${ }^{49}$ Para Sodré, tal grandeza literária residiria em dois fatores: por um lado, em sua biografia, já que a vida de Machado de Assis “acompanha o desenvolvimento econômico, político e social do país, naquela fase em que se esboça a sua fisionomia nacional"so e, por isso, o escritor "conhecerá todas as etapas que pode um escritor percorrer naquela fase, vindo da tipografia à Academia"; 51 por outro lado, na obra machadiana, que "refletirá [...] com uma clareza e com uma fidelidade absolutas, tudo aquilo que movimentou e que enriqueceu a fase a que assistiu e de que se tornaria uma das grandes testemunhas".52

Mesmo a interpretação de Coutinho da literatura brasileira a partir das ideias lukacsianas pode ter encontrado respaldo ${ }^{53}$ na leitura de Sodré, pois, como afirma Frederico (2007), havia a presença dessas ideias desde a reedição atualizada de História da literatura brasileira:

[...] a mais significativa referência a Lukács já havia sido feita em 1960 pelo respeitável intelectual marxista Nelson Werneck Sodré, na edição atualizada de sua História da literatura brasileira. [...] O conhecido historiador incorporou explicitamente diversas ideias lukacsianas em sua interpretação da história literária. Graças ao pioneirismo e ao prestígio de Nelson Werneck Sodré, Lukács ingressou, em grande estilo, nos estudos da literatura brasileira. ${ }^{54}$

Um posicionamento tão explícito em favor de uma leitura social da literatura só poderia afastar Carlos Nelson Coutinho das abordagens formalistas. Contra elas o crítico se opôs diretamente em $O$ estruturalismo e a miséria da razão. ${ }^{55}$ Nesse sentido, a ado-

\footnotetext{
49 Idem, p. 497.

50 Idem, p. 498.

51 Idem, p. 499.

52 Ibidem.

53 Respaldo devido à importância de Nelson Werneck Sodré na esquerda brasileira. No entanto, Konder (2008) afirma o pioneirismo de Carlos Nelson Coutinho na assimilação do método de Lukács no Brasil. 54 Frederico, Celso, op. cit., p. 191.

55 Coutinho, Carlos Nelson. O estruturalismo e a miséria da razão. Rio de Janeiro: Paz e Terra, 1972.
} 
ção das ideias lukacsianas também "servia de suporte teórico na luta ideológica contra [...] o formalismo, estruturalismo e positivismo (em voga nos anos 70 )".${ }^{66} \mathrm{O}$ suporte teórico seria fundamental para o autor que buscava, na contracorrente (para usar uma expressão cara ao próprio Coutinho), construir uma crítica ao estruturalismo. Como analisou Frederico (2007):

Carlos Nelson Coutinho, numa época difícil, enfrentou, praticamente sozinho, a vaga estruturalista que assolava o país, através do livro O estruturalismo e a miséria da razão (Editora Paz e Terra, 1972). As peripécias para conseguir um editor para a obra foram um capítulo à parte na história da censura e da autocensura, em época de repressão política e acovardamento geral.57

Em O estruturalismo e a miséria da razão, Coutinho afirma que pretende "analisar o estruturalismo à luz de uma posição mais universal, mais dialética, capaz de superar simultaneamente as unilateralidades estruturalistas e irracionalistas (ou para-irracionalistas)" $.5^{8} \mathrm{O}$ referencial é novamente lukacsiano, inspirado em A destruição da razão, obra em que Lukács faz uma crítica ao irracionalismo.

A análise de Coutinho (1972) volta-se aos estruturalistas franceses, Lévi-Strauss, Foucault, Althusser e, no âmbito do estruturalismo literário, Barthes. Coutinho (1972) relaciona a adaptação de Barthes do estruturalismo à literatura às correntes de leitura imanente da obra de arte, considerando-a "uma versão up to date do velho formalismo tecnicista", 59 na qual, "em vez de conhecimento da realidade, a literatura converte-se em técnica burocrática". ${ }^{60}$

Embora forneça elementos para uma crítica ao estruturalismo literário, não é esse o objeto do livro e, por isso, Coutinho (1972) não aborda na obra os efeitos da "vaga estruturalista” para a crítica literária brasileira. É certo, porém, que a crítica ao estruturalismo, os ensaios de crítica literária e os estudos do pensamento social brasi-

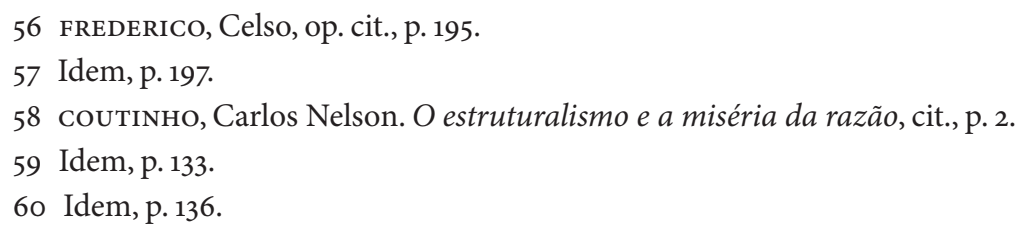


leiro formam um todo coerente, que Rafael Massuia ${ }^{61}$ considerou compor-se de "uma unidade fundamental".

Para Massuia, ainda que "tenha ficado restrita ao período histórico na qual foi concebida" e, além disso, que sua produção esteja "restrita a um período de sua atividade intelectual", a crítica literária de Coutinho "colocou-se a árdua tarefa de estabelecer bases para uma compreensão totalizante da literatura brasileira". ${ }^{62}$

Ao que tudo indica, a crítica literária de Carlos Nelson Coutinho restringe-se a determinado tempo e determinado tema, tanto por sua produção concentrada em um período específico (1965-1977), como por seus limites críticos. De todo modo, isso não retira da produção de Carlos Nelson Coutinho a capacidade de expressar e revelar problemas (críticos, metodológicos e ideológicos) de uma geração, o que pode ser observado no fato de que tanto os referenciais teóricos da crítica marxista como o empenho em discutir o sentido político da obra machadiana estão presentes e se desenvolvem em outros críticos machadianos do período.

Os ensaios sobre literatura de Carlos Nelson Coutinho expressam, além disso, o impacto do marxismo sobre a crítica brasileira ao propiciar, mais do que um instrumental teórico com que estudar a literatura, um debate acerca do lugar e do papel da crítica literária.

É claro que a problematização da função da crítica literária não se limita aos escritos de Coutinho, nem aos anos 1970, nem aos referenciais teóricos marxistas. Tampouco os questionamentos e as contribuições construídas em torno do realismo na obra machadiana derivam exclusivamente das chamadas "interpretações sociais" ou dos críticos "de esquerda". Pelo contrário, trata-se mais propriamente de um movimento de disputa capaz de elaborar algumas das principais interpretações da obra machadiana.

Tratava-se também de o estudo da obra machadiana exigir uma interpretação condizente com os tempos sombrios dos anos 1970. O interesse pela realidade brasileira e o interesse por Machado de Assis se aliavam, desse modo, no estudo do realismo do escritor. Como explicita Alfredo Bosi, não se tratava simplesmente da condição pessoal de um ou outro crítico do período, mas do "ethos de uma geração

61 massuia, Rafael. “Carlos Nelson Coutinho e a literatura brasileira”. Iv Conali - Congresso Nacional de Linguagens em Interação - Múltiplos Olhares, 5, 6 e 7 jun. 2013, p. 10.

62 Idem, p. 11. 
que compartilhou durante algum tempo as mesmas perplexidades no plano das ideias e no plano dos valores". ${ }^{63}$

Gabriela Manduca Ferreira é Doutora em Literatura Brasileira pela Universidade de São Paulo

63 Bosı, Alfredo. "Formações ideológicas na cultura brasileira". Estudos Avançados, n. 9, vol. 25, pp. 275-93, 1995, p. 275. 